\title{
Response and Adaptation of Microbial Community in a CANON Reactor Exposed to an Extreme Alkaline Shock
}

\author{
Ruili Yang, ${ }^{1,2}$ Wenlong Mao, ${ }^{1,3}$ Xiaojun Wang ${ }^{1},{ }^{1}$ Zhaoji Zhang, ${ }^{1}$ Junbin Wu, ${ }^{1}$ \\ and Shaohua Chen ${ }^{1}{ }^{1}$ \\ ${ }^{1}$ CAS Key Laboratory of Urban Pollutant Conversion, Institute of Urban Environment, Chinese Academy of Sciences, \\ Xiamen 361021, China \\ ${ }^{2}$ University of Chinese Academy of Sciences, Beijing 100049, China \\ ${ }^{3}$ Fujian Agriculture and Forestry University, Fuzhou 350002, China \\ Correspondence should be addressed to Xiaojun Wang; xjwang@iue.ac.cn and Shaohua Chen; shchen@iue.ac.cn
}

Received 22 April 2020; Revised 27 May 2020; Accepted 4 June 2020; Published 1 July 2020

Academic Editor: Rong Chen

Copyright (c) 2020 Ruili Yang et al. This is an open access article distributed under the Creative Commons Attribution License, which permits unrestricted use, distribution, and reproduction in any medium, provided the original work is properly cited.

Responses of a microbial community in the completely autotrophic nitrogen removal over nitrite (CANON) process, which was shocked by a $\mathrm{pH}$ of 11.0 for $12 \mathrm{~h}$, were investigated. During the recovery phase, the performance, anaerobic ammonia oxidation (anammox) activity, microbial community, and correlation of bacteria as well as the influencing factors were evaluated synchronously. The performance of the CANON process deteriorated rapidly with a nitrogen removal rate $(\mathrm{NRR}) \mathrm{of} 0.13 \mathrm{~kg} \cdot \mathrm{m}^{-3} \cdot \mathrm{d}^{-1}$, and Firmicutes, spore-forming bacteria, were the dominant phyla after alkaline shock. However, it could self-restore within 107 days after undergoing four stages, at which Planctomycetes became dominant with a relative abundance of $64.62 \%$. Network analysis showed that anammox bacteria (Candidatus Jettenia, Kuenenia, and Brocadia) were positively related to some functional bacteria such as Nitrosomonas, SM1A02, and Calorithrix. Canonical correspondence analysis presented a strong correlation between the microbial community and influencing factors during the recovery phase. With the increase of nitrogen loading rate, the decrease of free nitrous acid and the synergistic effects, heme c content, specific anammox activity (SAA), NRR, and the abundance of dominant genus increased correspondingly. The increase of heme $\mathrm{c}$ content regulates the quorum sensing system, promotes the secretion of extracellular polymeric substances, and further improves SAA, NRR, and the relative abundance of the dominant genus. This study highlights some implications for the recovery of the CANON reactor after being exposed to an alkaline shock.

\section{Introduction}

A completely autotrophic nitrogen removal over nitrite (CANON) process, a combination of partial nitritation and anaerobic ammonia oxidation (anammox), is highly sensitive to key environmental parameters, such as nitrite $\left(\mathrm{NO}_{2}{ }^{-} \mathrm{N}\right)$, dissolved oxygen (DO), and $\mathrm{pH}$ [1-3]. Although these parameters are always automatically controlled in engineering applications [4], a fortuitous occurrence of the CANON process can happen accidentally when the automatic control fails. In particular, $\mathrm{pH}$ as a crucial parameter can adversely affect the performance of the CANON process if it is not well controlled. In addition, substrate inhibition, which refers to the toxicity of free ammonia (FA) and free nitrous acid
(FNA) in the CANON process, is $\mathrm{pH}$-dependent [5]. Therefore, $\mathrm{pH}$ can have a strong effect on the CANON process [6]. Research on the effect of alkaline shock on the CANON process often uses $\mathrm{pH}<10.0$ [7-9]. Fux et al. [10] pointed out that specific anammox activity (SAA) of anammox was completely inhibited by $\mathrm{pH}$ 9.3. Li et al. [11] observed the disintegration of anammox granule at $\mathrm{pH} 9.0$. When the concentration of FA reaches approximately $32.5 \mathrm{mg} \cdot \mathrm{L}^{-1}$ at pH 8.5, anammox bacteria and ammonia oxidising bacteria (AOB) activities are severely inhibited, and the performance of the CANON system deteriorates quickly [9]. Apart from $\mathrm{pH}$ influence, the microbial community is known as an essential factor affecting the efficiency of the CANON process, and the structure of microbial communities is very 
sensitive to an alkaline situation [12]. In spite of this, studies about the CANON system are mainly focused on the nitrogen removal performance and abundances of anammox bacteria, AOB, and nitrite oxidising bacteria (NOB) $[13,14]$. Limited studies have considered the interaction of anammox bacteria, AOB, NOB, and denitrifying bacteria (DNB) [15]. $\mathrm{Wu}$ et al. [15] observed that the abundance of Sphingobacteria, which is closely related to aerobic denitrifying bacteria, in the CANON system was much higher than that in the anammox system when incubated with anaerobic sludge. Moreover, correlation among the microbial communities in the CANON system in response to alkaline shock remains to be studied in depth. In addition, $\mathrm{pH}$ is found to inhibit microbial communities in two ways: (1) $\mathrm{pH}$ inhibits the microbial activity by changing the characteristics of microbial habitats [16], and (2) $\mathrm{pH}$ inhibits microorganisms directly or via changing the concentrations of FA, FNA, and organics to inactivate irreversible enzymes, obstruct metabolic function, and reduce transcriptional activity [12]. Although the mechanisms of $\mathrm{pH}$ effects on the microbial community have been well studied, a few studies have focused on the response of microbial communities during the recovery phase in the CANON process when exposed to alkaline shock.

In this study, we hypothesised that synergy effects among the bacteria associated with the nitrogen cycle would improve the performance of the CANON process after applying transient alkaline $\mathrm{pH}$ shock. To test this hypothesis, the CANON process was exposed to an alkaline shock of $\mathrm{pH} 11.0$ for $12 \mathrm{~h}$. The nitrogen removal performance, activity indicators (SAA, heme c, extracellular polymeric substances (EPS), and signalling molecule), variation of the microbial community structure, correlation among the microorganisms, and the correlation between the microbial community and the influencing factors in the CANON reactor were investigated during the whole recovery process. This study is aimed at broadening our current knowledge of the underlying mechanisms of the microbial community in response to an alkaline shock and encouraging technical regulations optimising the CANON process for a maximal efficiency during the recovery process.

\section{Materials and Methods}

2.1. Experimental Setup and Reactor Operation. A pilot-scale upflow anaerobic filter (UAF) reactor (Figure 1) was used in this study. It had a working volume of $100 \mathrm{~L}$ and an internal diameter of $30 \mathrm{~cm}$ and was filled with polypropylene pall rings as biological carriers. A flexible electrical heating belt was adopted to maintain the temperature at $35 \pm 1^{\circ} \mathrm{C}$ and protect anammox bacteria against the competition of photosynthetic microorganisms. The hydraulic retention time (HRT) of the UAF reactor was set at 1 day. The $\mathrm{pH}$ and DO were controlled by an online controller and maintained at 7.4-7.8 and $0.02-0.8 \mathrm{mg} \cdot \mathrm{L}^{-1}$, respectively [7]. The inoculation sludge was taken from an anammox reactor, and its concentrations of mixed liquor suspended solid (MLSS) and mixed liquor volatile suspended solid (MLVSS) were approximately 22.87 and $12.49 \mathrm{~g} \cdot \mathrm{L}^{-1}$, respectively.
The CANON process was cultivated using synthetic wastewater, and the mineral medium was supplied according to our previous study [17]. After stable operation for $1.5 \mathrm{y}$, the CANON process showed a good performance with ammonium removal efficiency and nitrogen removal rate (NRR) of $93.74 \%$ and $0.80 \mathrm{~kg} \cdot \mathrm{m}^{-3} \cdot \mathrm{d}^{-1}$, respectively. Then, it was exposed to a transient alkaline shock of $\mathrm{pH} 11.0$ for $12 \mathrm{~h}$. The recovery phase mainly consisted of four stages: accommodation stage (days 1-37), anammox recovery stage (days 38-68), CANON recovery stage (days 69-100), and steady stage (days 101-107), according to the nitrogen removal performance of the CANON reactor and a previously reported method by Zhang et al. [18]. The operating conditions of the CANON process during the recovery phase are summarised in Table 1 . To ensure the recovery of anammox bacteria activity, first, we inhibited aeration and adjusted the $\mathrm{pH}$ to 7.8 by washing bioreactor with the synthetic wastewater without $\mathrm{NH}_{4}{ }^{+}-\mathrm{N}$ and $\mathrm{NO}_{2}{ }^{-}-\mathrm{N}$ for approximately $1 \mathrm{~h}$ at a flow rate of $1600 \mathrm{~mL} \cdot \mathrm{min}^{-1}$. The influent concentrations of $\mathrm{NH}_{4}{ }^{+}-\mathrm{N}$ and $\mathrm{NO}_{2}{ }^{-}-\mathrm{N}$ were decreased to $250 \mathrm{mg} \cdot \mathrm{L}^{-1}$ to avoid the substrate inhibition [19]. Next, the operating conditions (Table 1) were implemented according to the performance of the CANON reactor.

2.2. Sample Collection and Analysis. SAA, an important parameter to evaluate the performance of the anammox pathway [8], and heme $c$, an indispensable part of the key enzymes [20] directly associated with the substance and energy metabolism of anammox bacteria [21, 22], were used to codetermine the activity of anammox bacteria [23]. EPS, as the stress resister and indicator of the stability and settling property of anammox sludge, coupled with the signalling molecule, are secreted as the metabolites of microorganisms and are beneficial for the formation of biofilm [24, 25]. In this study, EPS was beneficial for initiating the CANON system [26]. The settleability and strength of granule sludge or biofilm are usually evaluated by the ratio of protein $(\mathrm{PN})$ to polysaccharides (PS) [27]. All these factors were used to evaluate the recovery of the CANON process.

Sludge and water samples were withdrawn from the CANON process on days $1,37,53,63,75,85$, and 107 , in order to investigate the EPS concentration, SAA, heme c content, and signalling molecule. Sample collection was conducted in triplicate. Concentrations of EPS and heme $c$ were determined based on the previous reports by $\mathrm{Ma}$ et al. [28] and Berry and Trumpower [29], respectively. The semiquantitative estimation of signalling molecule was determined according to the method proposed by Yeon et al. [30]. SAA was conducted according to our previous investigation [31]. Simultaneously, the concentrations of MLSS, MLVSS, ammonia $\left(\mathrm{NH}_{4}{ }^{+}-\mathrm{N}\right)$, nitrite $\left(\mathrm{NO}_{2}{ }^{-}-\mathrm{N}\right)$, nitrate $\left(\mathrm{NO}_{3}{ }^{-} \mathrm{N}\right)$, and total nitrogen $(\mathrm{TN})$ were analysed based on standard methods [32].

2.3. DNA Extraction and Amplicon Sequencing. To investigate responses of microbial communities in the CANON process to the exposure of an alkaline shock, sludge samples collected from the reactor on days 1, 37, 63, and 107 were subjected to DNA extraction, and quality control was also 


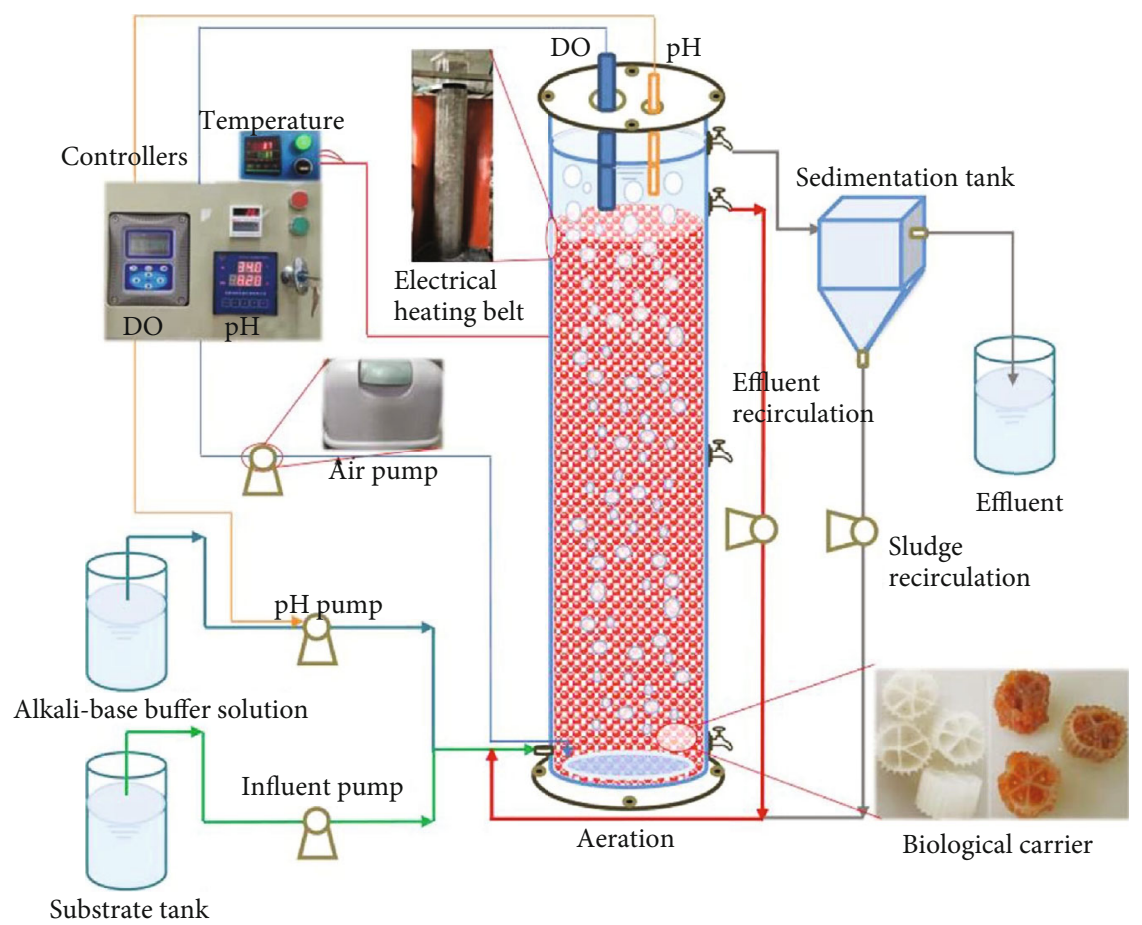

FIgURE 1: Schematic of the experimental device.

TABLE 1: Operational conditions of the CANON process after the alkaline shock.

\begin{tabular}{|c|c|c|c|c|c|}
\hline Stage & Time $(\mathrm{d})$ & $\mathrm{NH}_{4}{ }^{+}-\mathrm{N}\left(\mathrm{mg} \cdot \mathrm{L}^{-1}\right)$ & $\mathrm{NO}_{2}^{-}{ }^{-} \mathrm{N}\left(\mathrm{mg} \cdot \mathrm{L}^{-1}\right)$ & $\operatorname{NLR}\left(\mathrm{kg} \cdot \mathrm{m}^{-3} \cdot \mathrm{d}^{-1}\right)$ & $\mathrm{DO}\left(\mathrm{mg} \cdot \mathrm{L}^{-1}\right)$ \\
\hline \multirow{2}{*}{ Accommodation stage } & $1-3$ & 250 & 250 & 0.5 & \multirow{5}{*}{$<0.05$} \\
\hline & $4-37$ & 100 & 100 & 0.2 & \\
\hline \multirow{3}{*}{ Anammox recovery stage } & $38-61$ & 100 & 100 & 0.2 & \\
\hline & $62-64$ & 150 & 150 & 0.3 & \\
\hline & $65-68$ & 250 & 250 & 0.5 & \\
\hline \multirow{4}{*}{ CANON recovery stage } & $69-76$ & 450 & 150 & 0.6 & \multirow{5}{*}{$0.2-0.8$} \\
\hline & $77-81$ & 600 & 0 & 0.6 & \\
\hline & $82-86$ & 800 & 0 & 0.8 & \\
\hline & $87-100$ & 1000 & 0 & 1 & \\
\hline Steady stage & $101-107$ & 1000 & 0 & 1 & \\
\hline
\end{tabular}

performed according to our previous study [17]. Next, the V3-V4 hypervariable region of $16 \mathrm{~S}$ rDNA gene of the qualified DNA samples was selected for polymerase chain reaction (PCR) amplification using the universal primer sets: $341 \mathrm{~F}\left(5^{\prime}\right.$ -CCT ACG GGN GGC WGC AG-3') and 806R (5' -GGA CTA CHV GGG TAT CTA AT- $3^{\prime}$ ) [17]. PCR amplifications were conducted in triplicate, and the products were quantified using a Qubit 2.0 fluorometer (Promega Co., Madison, USA). The purified amplicons were pooled together in an equal amount. Then, the sequencing library was constructed and sent for paired end sequencing on a Hiseq2500 PE250 platform (Gene Denovo Biotechnology Co., Ltd., Guangzhou, China). The sequence data were processed using the Quantitative Insights into Microbial Ecology software [33], and results were assigned to operational taxonomic units (OTUs) with $>97 \%$ similarity.

2.4. Statistical and Network Analyses. Canonical correspondence analysis (CCA) was conducted to further explore the relationship between microbial communities and influencing factors using the "vegan" package in RStudio environment (https://www.rstudio.com/). Pairwise Spearman's correlation coefficients among 12 genera, which have an average abundance higher than $1 \%$, were calculated by SPSS Statistics 22 (IBM, USA) (http://www.ibm.com/analytics/us/en/technology/ spss/). Furthermore, network analysis based on Spearman's correlation coefficient $(r)>0.6$ or $<-0.6$, and the corresponding $p$ value $<0.05$ between two genera was performed 


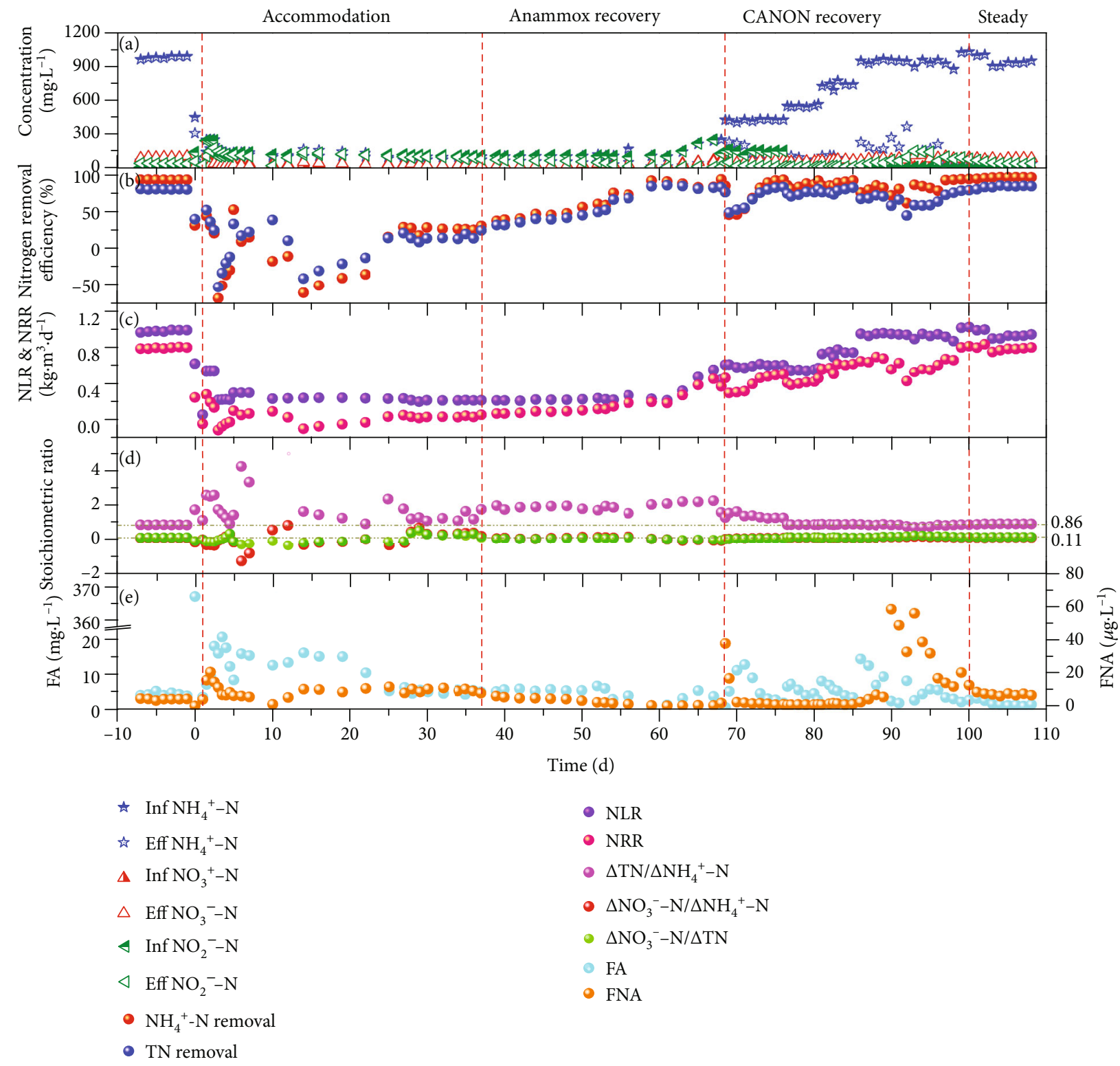

FIGURE 2: Shifts in nitrogen concentration (a), nitrogen removal efficiency (b), nitrogen loading rate and removal rate (c), stoichiometric ratio (d), and free ammonia and free nitrous acid (e) of the CANON process after alkaline shock.

and visualised by Gephi software (version 0.9.2, https://gephi .org/) [34].

\section{Results and Discussion}

3.1. Performance of the CANON Process during the Recovery Phase after Alkaline Shock. Figure 2 shows the nitrogen removal performance of the CANON reactor during the experiment. As depicted by Figure 2, the FA concentration of the CANON reactor sharply increased from $3.81 \mathrm{mg} \cdot \mathrm{L}^{-1}$ to $367.08 \mathrm{mg} \cdot \mathrm{L}^{-1}$, which was much higher than inhibition thresholds of $\mathrm{AOB}$ and anammox bacteria after being exposed to alkaline shock of $\mathrm{pH} 11.0$ for $12 \mathrm{~h}[1,9]$. Thus, the CANON process was severely inhibited by the alkaline shock. As Li et al. [11] reported, the effect of an alkaline $\mathrm{pH}$ (9.0) shock on the performance of anammox granular sludge was much more severe than that of an acidic $\mathrm{pH}$ (6.5) shock, and the alkaline condition disintegrated anammox granules. Based on the impact of influent $\mathrm{pH}$ of 4 and 10 for $12 \mathrm{~h}, \mathrm{Yu}$ and Jin [35] also found a loss of anammox performance only in alkaline condition. In addition to the increase of FA, researchers suggested that activity loss could be related on the unavailability of trace elements as caused by extreme alkaline condition [35, 36]. Subsequently, aeration, $\mathrm{pH}$, and influent concentrations of $\mathrm{NH}_{4}^{+}-\mathrm{N}$ and $\mathrm{NO}_{2}^{-}-\mathrm{N}$ were adjusted according to Table 1. Despite this, a progressive deterioration of the nitrogen removal performance was still observed, and the concentration of effluent TN was $41.21 \%$ higher than that of influent at the early accommodation stage (days 1-14). However, in the late accommodation stage (days 15-37), the CANON system gradually adapted to the changed environment. 

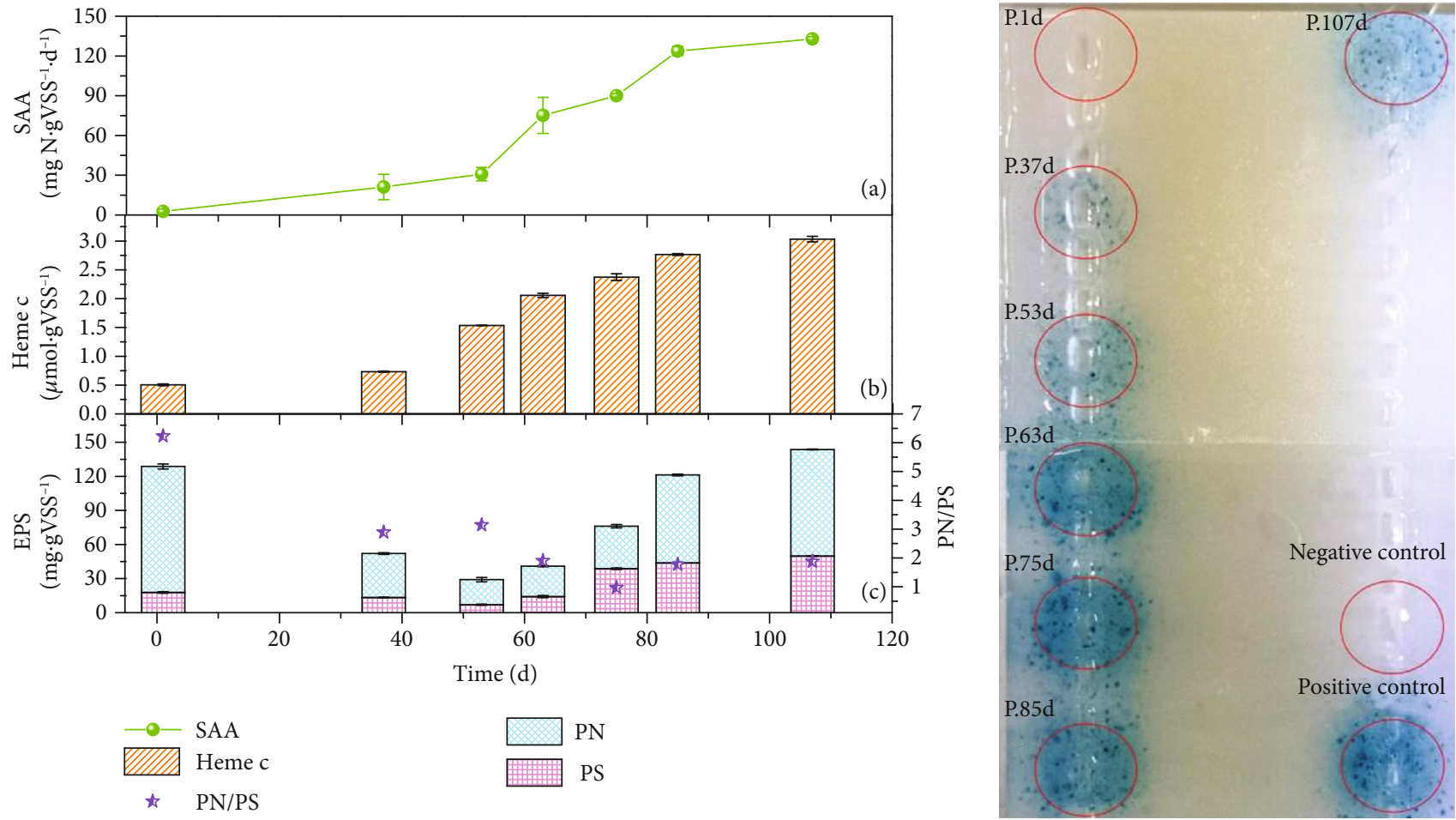

(d)

Figure 3: Variations of SAA (a), heme c (b), EPS (c), and signalling molecule (d) content in the CANON process after alkaline shock.

On days 38-52, the nitrogen removal performance of the anammox process recovered slowly with an increase of nitrogen removal efficiency (NRE) from $32 \%$ to $49.67 \%$. Afterwards, the NRE and NRR increased rapidly to $86.44 \%$ and $0.18 \mathrm{~kg} \cdot \mathrm{m}^{-3} \cdot \mathrm{d}^{-1}$, respectively, within 9 days. This phenomenon was similar to the lag stage in the start-up of the anammox process [37]. On days 62-68, the anammox process was enhanced rapidly with NRR increasing from 0.18 to $0.45 \mathrm{~kg} \cdot \mathrm{m}^{-3} \cdot \mathrm{d}^{-1}$. To improve the nitrogen removal performance of the CANON system during the recovery stage (days 69-100), DO was maintained at $0.2-0.8 \mathrm{mg} \cdot \mathrm{L}^{-1}$. As expected, the NRR increased to $0.82 \mathrm{~kg} \cdot \mathrm{m}^{-3} \cdot \mathrm{d}^{-1}$ and NRE was at around $72 \%$. Simultaneously, the stoichiometric ratios of $\Delta \mathrm{TN} /$ $\Delta \mathrm{NH}_{4}{ }^{+}-\mathrm{N}, \Delta \mathrm{NO}_{3}{ }^{-}-\mathrm{N} / \Delta \mathrm{NH}_{4}{ }^{+}-\mathrm{N}$, and $\Delta \mathrm{NO}_{3}{ }^{-} \mathrm{N} / \Delta \mathrm{TN}$ gradually increased from $1.29,0.10$, and 0.10 , respectively, on day 1 , to their theoretical value $(0.86,0.11$, and 0.127 , respectively), as described in the relevant studies $[8,38]$. This meant there was significant synergy between AOB and anammox bacteria and there was no excess proliferation of NOB in the CANON reactor. In addition, the effect of the FNA fluctuation $\left(>15 \mu \mathrm{g} \cdot \mathrm{L}^{-1}\right)$ on nitrogen removal performance was more significant $(p<0.05)$ than that of the FA fluctuation on days 62-68. Previous studies report the FNA inhibition of AOB activity to be $100 \mu \mathrm{g} \cdot \mathrm{L}^{-1}$ [9], whereas the inhibition on anammox bacteria activity is approximately $15 \mu \mathrm{g} \cdot \mathrm{L}^{-1}$ [1]. Deterioration of the CANON performance, which was affected by FNA fluctuation, could be explained by this reason during the recovery phrase of the CANON system. He et al. [1] also pointed out that the anammox pathway, after being exposed to transient $\mathrm{pH}$ (9.0) shock, could be recov- ered rapidly by simultaneously increasing nitrogen loading rate (NLR) and decreasing FNA $\left(<15 \mu \mathrm{g} \cdot \mathrm{L}^{-1}\right)$.

At the steady stage (days 101-107), the water quality of effluent and stoichiometric ratios became stable, and the nitrogen removal performance was even better than the initial level where the averages of NRE and NRR increased to $83.28 \%$ and $0.80 \mathrm{~kg} \cdot \mathrm{m}^{-3} \cdot \mathrm{d}^{-1}$, respectively. The sensibility, low biomass yield, and slow growth rate of anammox bacteria were the main challenges for the application of the CANON process [8], though autotrophic bacteria of $\mathrm{AOB}$ and anammox bacteria were simultaneously grown in a single reactor [39]. Recovery of anammox bacteria should be focused on after the CANON reactor is exposed to an alkaline shock.

3.2. Changes of SAA, Heme c, EPS, and Signalling Molecule during the Recovery of the CANON Process after Alkaline Shock. Shifts in SAA, heme c, EPS, and signalling molecule content of the CANON process are shown in Figure 3. The SAA and heme $c$ were maintained at low levels of $2.75 \mathrm{mg} \mathrm{N} \cdot \mathrm{g}^{-1} \mathrm{VSS} \cdot \mathrm{d}^{-1}$ and $0.50 \mu \mathrm{mol} \cdot \mathrm{g}^{-1} \mathrm{VSS}$, respectively, on day 1 . It was clear that approximately $98 \%$ of anammox activity was lost compared to the activity in the initial phase. In the meantime, signalling molecule content was nearly zero, which was the quickest response to the transient alkaline shock. The signalling molecule was easily affected by the $\mathrm{pH}$ and quickly degraded under alkaline conditions [40]. It implied that AOB and anammox bacteria were inactivated, which was also supported by the performance of low NRE and NRR on day 1 in the CANON reactor. However, there was a delayed change in EPS, with a high concentration 
of $128.76 \mathrm{mg} \cdot \mathrm{g}^{-1} \mathrm{VSS}$ on day 1 . This was likely because some microbial members excreted excessive EPS. Subsequently, the signalling molecule-based quorum sensing (QS) system could not regulate EPS production normally after being adversely influenced by the extreme alkaline shock [11,40]. Previous studies $[41,42]$ have reported that the signalling molecule-based QS system could regulate EPS secretion under normal conditions. Subsequently, these parameters were gradually recovered during the recovery phase.

Significant increases of SAA, heme $c$, and the signalling molecule were observed on days 53-63,37-53, and 53-63, respectively, during which the corresponding NRE were being recovered from $53 \%$ to $85 \%$. This meant the anammox bacteria and AOB activities were recovered gradually. Moreover, the recovery time of heme $\mathrm{c}$ was shorter than that of the other parameters. Heme $c$ is an important component of hydrazine synthesis, hydroxylamine oxidoreductase, and hydrazine oxidase in purified anammox cells [21]. It is directly associated with the metabolism of substances and energy in anammox bacteria [21,22], and it also determines the activity of anammox biomass [23]. Chen et al. [43] found a similar result in an anammox-EGSB recovery system which experienced a longer-term starvation. Badalamenti et al. [44] reviewed one of 38 putative multiheme c-type cytochromes containing 69 heme-binding motifs and concluded that a LuxI/LuxR QS cassette can produce an unidentified signalling molecule. A signalling molecule-based QS system could regulate EPS secretion [41, 42]. Zhang et al. [45] confirmed that C8-HSL and C6-HSL, the examples of signalling molecules, favour EPS production and improve the activity of anammox bacteria, AOB, and others. Therefore, the enhancement of heme $\mathrm{c}$ was found to accelerate the secretion of a signalling molecule and promote the microbial activity $[21,44]$. As a result, an increase in EPS content was found following the changing pattern of the signalling molecule. On day 107, the concentrations of SAA, heme c, and EPS were increased to $132.86 \mathrm{mg} \mathrm{N} \cdot \mathrm{g}^{-1} \mathrm{VSS} \cdot \mathrm{d}^{-1}, 3.03 \mu \mathrm{mol} \cdot \mathrm{g}^{-1}$ VSS, and $143.65 \mathrm{mg} \cdot \mathrm{g}^{-1} \mathrm{VSS}$, respectively. Although these values were similar to the findings in previous studies $[45,46]$, they were much higher than the values at the initial levels $(p<0.01)$ after the alkaline shock in this study. The NLR, NRR, and NRE reached the maximum values, and the CANON system remained stable.

\subsection{Microbial Community Shift in the CANON Process after} Alkaline Shock. A shift in the microbial community structure of the CANON process after alkaline shock was investigated by amplicon sequencing. The OTU number and diversity index increased gradually as the CANON process resumed (Table 2). Figure 4(a) shows the bacterial community composition in the CANON process at the phylum level. As shown in Figure 4(a), Firmicutes was the dominant bacterial taxum with a relative abundance of $73.93 \%$ after the alkaline shock. A similar phenomenon was also observed by Callejas et al. [47] after a transient $\mathrm{pH}$ increase. Wang and $\mathrm{Gu}$ [48] reported that the effect of alkaline condition (9.0) on the microbial community structure of the anammox process was stronger than that of acid condition (5.0). Firmicutes are spore-forming bacteria and related to complex organic
TABLE 2: Characteristics of amplicon libraries.

\begin{tabular}{lcccccc}
\hline Group & OTUs & Shannon & Simpson & Chao & Ace & Coverage \\
\hline P1d & 758 & 5.04 & 0.912 & 812.0 & 854.41 & 0.998 \\
P37d & 780 & 4.81 & 0.829 & 842.4 & 884.32 & 0.998 \\
P63d & 1058 & 6.90 & 0.973 & 1096.8 & 1149.77 & 0.997 \\
P107d & 1063 & 5.15 & 0.843 & 1099.1 & 1152.35 & 0.998 \\
\hline
\end{tabular}

matter degradation, which could explain the resistance to cell lysis in an alkaline environment [47]. The recovery of the CANON process also experienced four stages according to the variations in the microbial community at the phylum's level. Proteobacteria and Bacteroidetes, which are involved in nitrogen removal and organic acid degradation [49], became the two dominant phyla with their relative abundances increasing from $4.33 \%$ to $71.63 \%$ and from $1.32 \%$ to $14.29 \%$, respectively, at the accommodation stage. Proteobacteria, Planctomycetes, and Bacteroidetes were the three dominant phyla at the growth stage, and the relative abundance of Planctomycetes increased from $2.28 \%$ to $16.87 \%$. On day 107, Planctomycetes became the dominant phyla with a relative abundance of $64.62 \%$, indicating that the CANON process had recovered to a certain degree. Wang et al. [50] also observed this phenomenon during the recovery of the CANON process when stressed by salt.

At the genus level (Figure 4(b)), Bacillus, belonging to Firmicutes, was the dominant genus with a relative abundance of $67.98 \%$ after the alkaline shock. Bacillus is a robust model organism for biofilm formation [51]. Bacillus can not only contribute to $\mathrm{O}_{2}$ removal [52], nitrate reduction [53], and organic matter degradation [54] but can also secrete EPS, especially EPS-PN, for increasing resistances to adverse environmental stresses [55]. All these factors may explain why the Bacillus survived after alkaline shock. The accommodation stage (days 1-37) in this study was analogous to the cell lysis stage in the start-up of the anammox process [56]. Thermomonas was capable of utilising the organic products from cell lysis [57]; therefore, it became the dominant genus at the accommodation stage. At the growth stage (days 38-61), the microbial diversity of the CANON process was consistently increasing. The relative abundances of anammox bacteria (Candidatus Jettenia, Kuenenia, and Brocadia) gradually increased from $0.13 \%$ to $7.52 \%$. After that, $\mathrm{AOB}$ (Nitrosomonas) together with anammox bacteria (Candidatus Jettenia, Kuenenia and Brocadia) became the dominant genera as aeration began. The relative abundances of $\mathrm{AOB}$ and anammox bacteria (Candidatus Jettenia +Kuenenia+Brocadia) at the enhancement stage increased quickly from $2.57 \%$ and $7.52 \%$ to $3.05 \%$ and $53.30 \%$, respectively. Excess proliferation of NOB was not detected throughout the experiment. The good performance of the CANON process could be explained through microbiological perspectives.

3.4. Correlations of Microbial Communities and the Influencing Factors in the CANON Process after Alkaline Shock. Network analysis is an effective analytical approach 


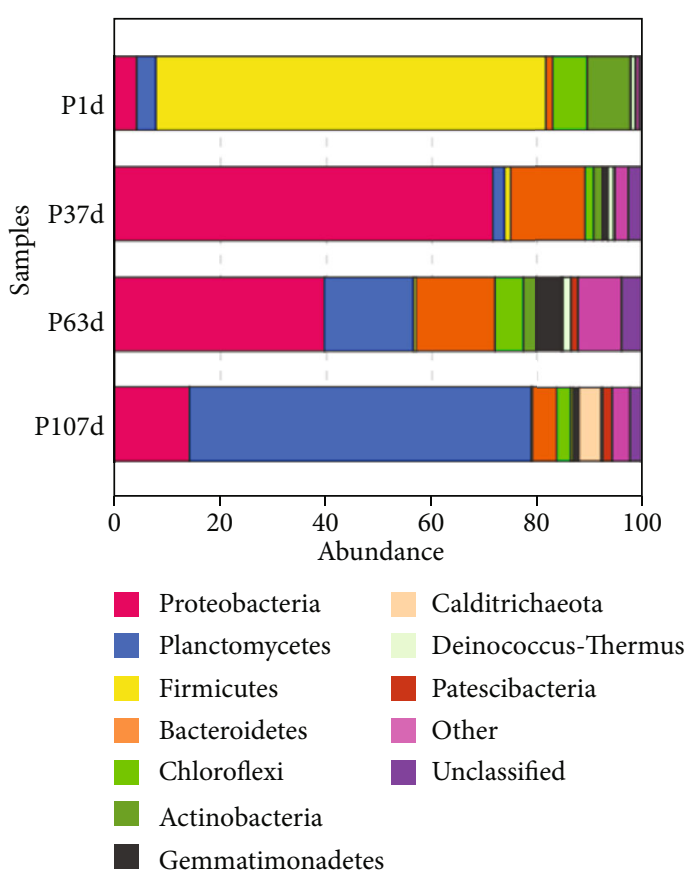

(a)

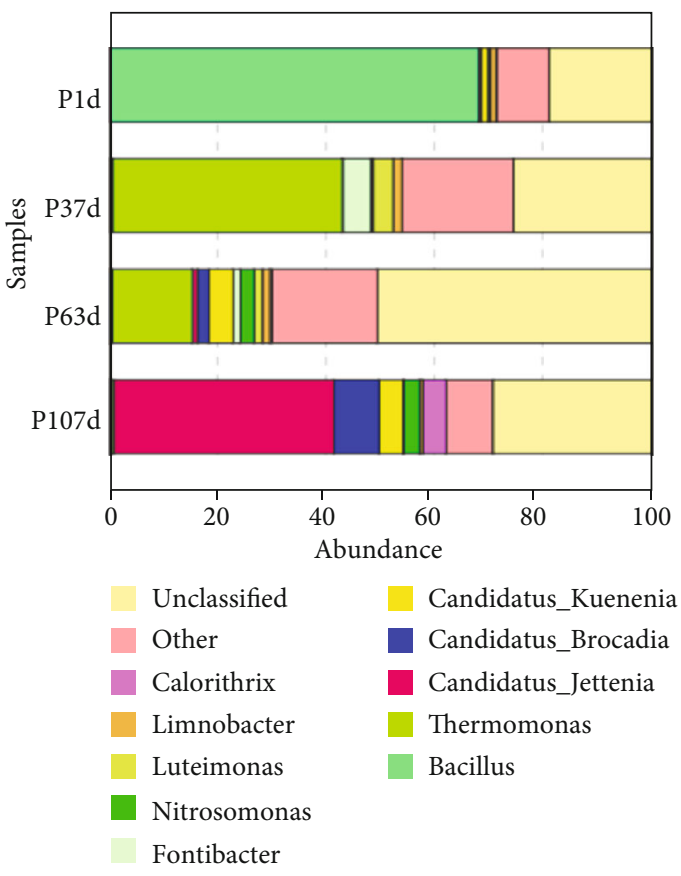

(b)

FIGURE 4: Bacterial community composition at the phylum (a) and genus (b) levels in the CANON process after alkaline shock.

for further exploring the correlation among the dominant microbial taxa (Figure $5(\mathrm{a})$ ) in the CANON process exposed to alkaline shock. As shown in Figure 5(a), the dominant flora was divided into three modules based on the Fruchterman-Reingold algorithm. Members in module A, which accounted for $50 \%$ of the network, were Candidatus Jettenia, Candidatus Kuenenia, Candidatus Brocadia, Nitrosomonas, SM1A02, and Calorithrix. They were positively related to each other $(p<0.05)$. Limnobacter, one genus of module $\mathrm{B}$, showed a significant negative correlation with Candidatus Jettenia, Candidatus Brocadia, Nitrosomonas, and Calorithrix $(p<0.05)$. Additionally, Bacillus was negatively correlated with all members in module A. CCA was further applied to determine the correlation of microbial communities and the influencing factors (Figure 5(b)) during the recovery phase. As is presented in Figure 5(b), the dominant genera of Candidatus jettenia, Candidatus Kuenenia, Candidatus Brocadia, SM1A02, and Calorithrix, had a significantly positive correlation $(p<0.05)$ with the influencing factors of SAA, NLR, NRR, heme $c$, EPS-PS, and FNA. Nitrosomonas was positively correlated with EPS, EPS-PN, SAA, NLR, NRR, heme c, EPS-PS, and FNA. However, Bacillus was only positively correlated with EPS-PN.

The abovementioned results can be explained by (1) the impact of NLR-led influencing factors, (2) synergistic effects of the dominant genus in the network module A, and (3) antagonistic effect of Limnobacter, Bacillus, and the dominant genus in network module A. As shown in Figure 5(c), anammox bacteria (Candidatus Jettenia, Brocadia, and Kuenenia) oxidised $\mathrm{NH}_{4}{ }^{+}-\mathrm{N}$ to $\mathrm{N}_{2}$ with $\mathrm{NO}_{2}{ }^{-}-\mathrm{N}$ and $\mathrm{CO}_{2}$, which were produced by AOB (Nitrosomonas) and DNB (Calorithrix), respectively. These served as the electron acceptors and inorganic carbon sources under anaerobic conditions $[49,58]$. As reported in previous studies, SM1A02 has the anammox ability and might be a novel anammox strain; therefore, it has the same synergistic effects with Nitrosomonas and Calorithrix [59-61]. In addition, Nitrosomonas can utilise $\mathrm{NH}_{4}^{+}-\mathrm{N}$ and $\mathrm{DO}$ and create anaerobic conditions for anammox bacteria such as SM1A02 and Calorithrix [49, 60]. Calorithrix provides a substrate of $\mathrm{NH}_{4}{ }^{+}-\mathrm{N}$ to anammox bacteria, $\mathrm{SM1A02}$, and Nitrosomonas by dissimilatory $\mathrm{NO}_{3}{ }^{-}$ $\mathrm{N}$ reduction to $\mathrm{NH}_{4}{ }^{+}-\mathrm{N}$ [58]. All members in module A could secrete EPS to protect the members from adverse environmental stresses [58-60]. With the increase of NLR, decrease of FNA, and enhancement of synergistic effects of the dominant genus on network module $\mathrm{A}$, it was observed that heme $\mathrm{c}$ content, SAA, NRR, and the relative abundance of dominant genus increased correspondingly [1, 21, 44, 45]. He et al. [1] reported that the anammox reactor recovered rapidly by simultaneously increasing NLR and decreasing FNA after experiencing a transient $\mathrm{pH}$ shock. However, Limnobacter competed with other functional bacteria for acetate, $\mathrm{O}_{2}$, and $\mathrm{NO}_{3}{ }^{-} \mathrm{N}$ [62] and consumed the EPS-PN produced by the members in module $\mathrm{A}$. This explains why Limnobacter deteriorated the resistance of the microbial community to adverse influences $[62,63]$ and was assigned to module B. In addition, Bacillus was eliminated in longterm anaerobic conditions with the increase of NLR and therefore was negatively correlated with module A [64]. The synergistic and antagonistic effects of these functional bacteria, coupled with the control of NLR, FA, and FNA, 


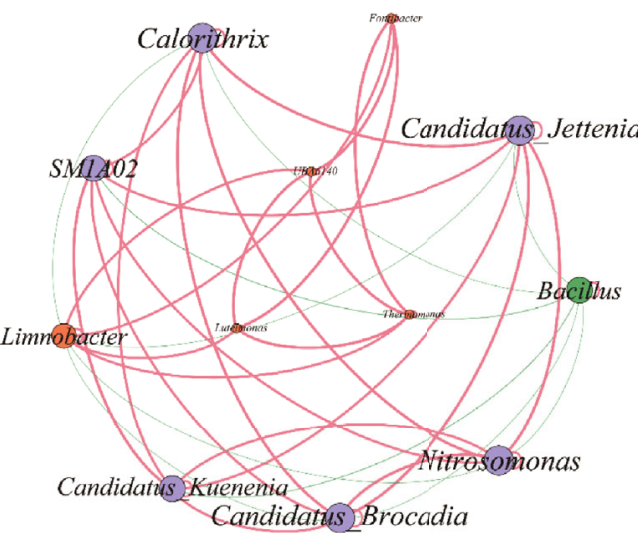

A $50.00 \%$

B $41.67 \%$

C $8.33 \%$

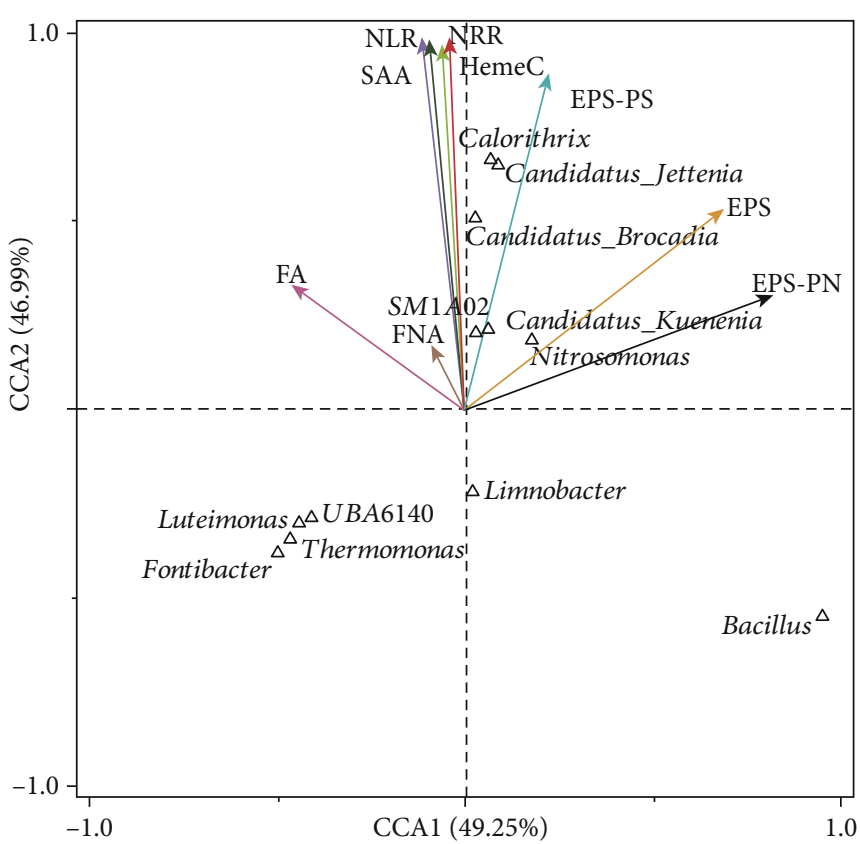

(b)

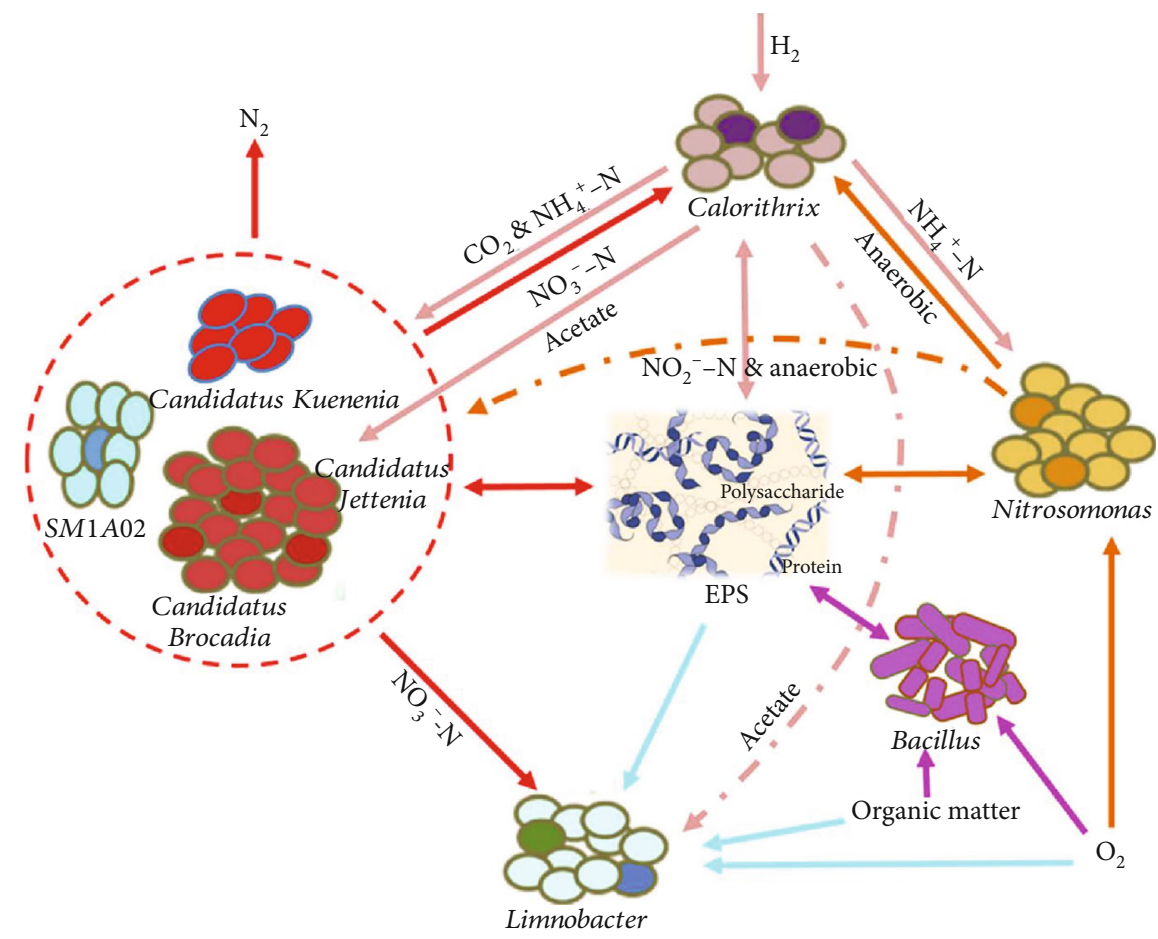

(c)

Figure 5: (a) Cooccurring network analysis of dominant microflora, (b) CCA of microbial communities and the influencing factors, and (c) correlation among dominant microflora, in the CANON process exposed to alkaline shock. The cooccurring network is coloured by the modularity class. Each node represents a dominant genus. Red and green lines represent positive and negative correlations, respectively. Node sizes are weighted by the node degree (numbers of connections).

codetermined the performance of the CANON process. All these supplied the underlying mechanisms of the microbial community in response to the alkaline shock. Meanwhile, these could also inform technical regulations optimising the CANON process for maximal efficiency during the recovery process. 


\section{Conclusions}

The CANON process was found to rapidly deteriorate after an alkaline shock of $\mathrm{pH} 11$. However, it could be selfrestored with the final NRR of $0.80 \mathrm{~kg} \cdot \mathrm{m}^{-3} \cdot \mathrm{d}^{-1}$ after the system underwent four stages (accommodation, anammox recovery, CANON recovery, and steady stages). During the entire recovery process, heme $\mathrm{c}$ content responded the fastest to the transient alkaline shock among all tested parameters and increased gradually, followed by the signalling molecule. Both parameters improved the AOB and anammox activity and regulated the EPS secretion. Firmicutes, a type of spore-forming bacterium, was dominant at the initial stage, and subsequently at the later period, Planctomycetes became the dominant phylum with a relative abundance of $64.62 \%$. Network analysis clearly revealed positive relationships among anammox bacteria (Candidatus Jettenia, Kuenenia, and Brocadia), AOB (Nitrosomonas), SM1A02, and DNB (Calorithrix). Additionally, there was a strong correlation between microbial communities and the influencing factors during the recovery phase. With the increase of NLR, decrease of FNA, and synergistic effects of dominant microbial members, heme c content, SAA, NRR, and the relative abundance of the dominant genus increased correspondingly. The increase of heme $c$ content regulates the quorum sensing system, promotes the secretion of EPS, and further improves SAA, NRR, and the relative abundance of the dominant genus. The response of the microbial community to environmental change gives an insight into the recovery of the CANON process after being exposed to an alkaline shock and provides technical regulations for its engineering application.

\section{Data Availability}

The data used to support the findings of this study are included within the article.

\section{Conflicts of Interest}

The authors declare that there is no conflict of interest regarding the publication of this article.

\section{Acknowledgments}

This research was financially supported by the National Natural Science Foundation of China (grant No. 51708536) and the Science and Technology Program of Fujian Province (grant No. 2019Y01010111).

\section{References}

[1] S. He, Y. Zhang, Q. Niu, H. Ma, and Y. Y. Li, "Operation stability and recovery performance in an Anammox EGSB reactor after pH shock," Ecological Engineering, vol. 90, pp. 50$56,2016$.

[2] X. Yue, G. Yu, Y. Lu et al., "Effect of dissolved oxygen on nitrogen removal and the microbial community of the completely autotrophic nitrogen removal over nitrite process in a sub- merged aerated biological filter," Bioresource Technology, vol. 254, pp. 67-74, 2018.

[3] A. O. Sliekers, K. A. Third, W. Abma, J. G. Kuenen, and M. S. M. Jetten, "CANON and Anammox in a gas-lift reactor," FEMS microbiology letters, vol. 218, no. 2, pp. 339-344, 2003.

[4] S. Lackner, E. M. Gilbert, S. E. Vlaeminck, A. Joss, H. Horn, and M. C. M. van Loosdrecht, "Full-scale partial nitritation/anammox experiences - An application survey," Water Research, vol. 55, pp. 292-303, 2014.

[5] S. He, Q. Niu, H. Ma, Y. Zhang, and Y. Y. Li, "The treatment performance and the bacteria preservation of anammox: a review," Water, Air, \& Soil Pollution, vol. 226, no. 5, 2015.

[6] X. Chang, D. Li, Y. Liang et al., "Performance of a completely autotrophic nitrogen removal over nitrite process for treating wastewater with different substrates at ambient temperature," Journal of Environmental Sciences, vol. 25, no. 4, pp. 688697, 2013.

[7] X. Yue, G. Yu, Z. Liu, J. Tang, and J. Liu, "Fast start-up of the CANON process with a SABF and the effects of $\mathrm{pH}$ and temperature on nitrogen removal and microbial activity," Bioresource Technology, vol. 254, pp. 157-165, 2018.

[8] T. V. Huynh, P. D. Nguyen, T. N. Phan et al., "Application of CANON process for nitrogen removal from anaerobically pretreated husbandry wastewater," International Biodeterioration \& Biodegradation, vol. 136, pp. 15-23, 2019.

[9] S. Li, Y. P. Chen, C. Li, J. S. Guo, F. Fang, and X. Gao, "Influence of free ammonia on completely autotrophic nitrogen removal over nitrite (CANON) process," Applied Biochemistry and Biotechnology, vol. 167, no. 4, pp. 694-704, 2012.

[10] C. Fux, V. Marchesi, I. Brunner, and H. Siegrist, "Anaerobic ammonium oxidation of ammonium-rich waste streams in fixed-bed reactors," Water Science and Technology, vol. 49, no. 11-12, pp. 77-82, 2004.

[11] J. Li, W. Zhu, H. Dong, and D. Wang, "Performance and kinetics of ANAMMOX granular sludge with $\mathrm{pH}$ shock in a sequencing batch reactor," Biodegradation, vol. 28, no. 4, pp. 245-259, 2017.

[12] C. Wang, S. Liu, X. Xu, Y. Guo, F. Yang, and D. Wang, "Role of cyclic diguanylate in affecting microbial community shifts at different $\mathrm{pH}$ during the operation of simultaneous partial nitrification, anammox and denitrification process," Science of The Total Environment, vol. 637-638, pp. 155162, 2018.

[13] W. Mi, J. Zhao, X. Ding, G. Ge, and R. Zhao, "Treatment performance, nitrous oxide production and microbial community under low-ammonium wastewater in a CANON process," Water Science and Technology, vol. 76, no. 12, pp. 34683477, 2017.

[14] X. Li, J. Zhang, X. Zhang, J. Li, F. Liu, and Y. Chen, "Start-up and nitrogen removal performance of CANON and SNAD processes in a pilot-scale oxidation ditch reactor," Process Biochemistry, vol. 84, pp. 134-142, 2019.

[15] P. Wu, X. Zhang, X. Wang, C. Wang, F. Faustin, and W. Liu, "Characterization of the start-up of single and two-stage Anammox processes with real low-strength wastewater treatment," Chemosphere, vol. 245, p. 125572, 2020.

[16] C. L. Lauber, M. Hamady, R. Knight, and N. Fierer, "Pyrosequencing-based assessment of soil $\mathrm{pH}$ as a predictor of soil bacterial community structure at the continental scale," Applied and Environmental Microbiology, vol. 75, no. 15, pp. 5111-5120, 2009. 
[17] R. Yang, X. Wang, Y. Guo, Z. Zhang, and S. Chen, "Evaluation of anammox pathway recovery after high COD loading using water quality, molecular biology and isotope labelling analysis," Bioprocess and Biosystems Engineering, vol. 43, no. 4, pp. 625-636, 2020.

[18] Q.-Q. Zhang, G.-F. Yang, H. Wang, K. Wu, R. C. Jin, and P. Zheng, "Estimating the recovery of ANAMMOX performance from inhibition by copper (II) and oxytetracycline (OTC)," Separation and Purification Technology, vol. 113, pp. 90-103, 2013.

[19] K. Isaka, T. Sumino, and S. Tsuneda, "High nitrogen removal performance at moderately low temperature utilizing anaerobic ammonium oxidation reactions," Journal of Bioscience and Bioengineering, vol. 103, no. 5, pp. 486-490, 2007.

[20] M. G. Klotz, M. C. Schmid, M. Strous, H. J. M. op den Camp, M. S. M. Jetten, and A. B. Hooper, "Evolution of an octahaem cytochrome c protein family that is key to aerobic and anaerobic ammonia oxidation by bacteria," Environmental Microbiology, vol. 10, no. 11, pp. 3150-3163, 2008.

[21] M. S. M. Jetten, L. van Niftrik, M. Strous, B. Kartal, J. T. Keltjens, and H. J. M. Op den Camp, "Biochemistry and molecular biology of anammox bacteria," Critical Reviews in Biochemistry and Molecular Biology, vol. 44, no. 2-3, pp. 65-84, 2009.

[22] M. C. Schmid, A. B. Hooper, M. G. Klotz et al., "Environmental detection of octahaem cytochrome c hydroxylamine/hydrazine oxidoreductase genes of aerobic and anaerobic ammonium-oxidizing bacteria," Environmental Microbiology, vol. 10, no. 11, pp. 3140-3149, 2008.

[23] Q. Q. Zhang, Y. H. Zhao, C. J. Wang et al., "Expression of the nirS, $h z s A$, and $h d h$ genes and antibiotic resistance genes in response to recovery of anammox process inhibited by oxytetracycline," Science of The Total Environment, vol. 681, pp. 5665, 2019.

[24] A. Alagely, C. J. Krediet, K. B. Ritchie, and M. Teplitski, "Signaling-mediated cross-talk modulates swarming and biofilm formation in a coral pathogen_Serratia marcescens_," The ISME Journal, vol. 5, no. 10, pp. 1609-1620, 2011.

[25] C. Wang, S. Liu, X. Xu, C. Zhao, F. Yang, and D. Wang, "Potential coupling effects of ammonia-oxidizing and anaerobic ammonium-oxidizing bacteria on completely autotrophic nitrogen removal over nitrite biofilm formation induced by the second messenger cyclic diguanylate," Applied Microbiology \& Biotechnology, vol. 101, no. 9, pp. 3821-3828, 2017.

[26] Z. Zhang, S. Chen, P. Wu, L. Lin, and H. Luo, "Start-up of the Canon process from activated sludge under salt stress in a sequencing batch biofilm reactor (SBBR)," Bioresource Technology, vol. 101, no. 16, pp. 6309-6314, 2010.

[27] X. Hou, S. Liu, and Z. Zhang, "Role of extracellular polymeric substance in determining the high aggregation ability of anammox sludge," Water Research, vol. 75, pp. 51-62, 2015.

[28] C. Ma, R. C. Jin, G. F. Yang, J. J. Yu, B. S. Xing, and Q. Q. Zhang, "Impacts of transient salinity shock loads on Anammox process performance," Bioresource Technology, vol. 112, pp. 124-130, 2012.

[29] E. A. Berry and B. L. Trumpower, "Simultaneous determination of hemes $a, b$, and $c$ from pyridine hemochrome spectra," Analytical Biochemistry, vol. 161, no. 1, pp. 1-15, 1987.

[30] K.-M. Yeon, W. S. Cheong, H. S. Oh et al., "Quorum sensing: a new biofouling control paradigm in a membrane bioreactor for advanced wastewater treatment," Environmental Science \& Technology, vol. 43, no. 2, pp. 380-385, 2009.
[31] X. Wang, R. Yang, Z. Zhang, J. Wu, and S. Chen, "Mass balance and bacterial characteristics in an in-situ full-scale swine wastewater treatment system occurring anammox process," Bioresource Technology, vol. 292, p. 122005, 2019.

[32] The State Environmental Protection Administration of China (SEPA), Editorial Committee of "monitoring and analytical methods of water and wastewater", China Environmental Science Press, Beijing, 4th edition, 2002.

[33] Y. H. Yang, Z. L. Lei, L. Huang et al., "Antitumor ability of berberine accompanied by modulation of gut microbiome in sarcoma-180 tumor-bearing mice," International Journal of Pharmacology, vol. 14, pp. 460-470, 2018.

[34] H. He, L. Fu, Q. Liu et al., "Community structure, abundance and potential functions of bacteria and archaea in the Sansha Yongle Blue Hole, Xisha, South China Sea," Frontiers in microbiology, vol. 10, 2019.

[35] J.-J. Yu and R.-C. Jin, "The ANAMMOX reactor under transient-state conditions: process stability with fluctuations of the nitrogen concentration, inflow rate, $\mathrm{pH}$ and sodium chloride addition," Bioresource Technology, vol. 119, pp. 166$173,2012$.

[36] G. M. Gadd and A. J. Griffiths, "Microorganisms and heavy metal toxicity," Microbial Ecology, vol. 4, no. 4, pp. 303-317, 1977.

[37] J. Guo, S. Wang, J. Lian et al., "Rapid start-up of the anammox process: effects of five different sludge extracellular polymeric substances on the activity of anammox bacteria," Bioresource Technology, vol. 220, pp. 641-646, 2016.

[38] X. Wang and D. Gao, "In-situ restoration of one-stage partial nitritation-anammox process deteriorated by nitrate build-up via elevated substrate levels," Scientific reports, vol. 6, 2016.

[39] X. Zhang, N. Zhang, H. Fu et al., "Effect of zinc oxide nanoparticles on nitrogen removal, microbial activity and microbial community of CANON process in a membrane bioreactor," Bioresource Technology, vol. 243, pp. 93-99, 2017.

[40] A. W. Decho, P. T. Visscher, J. Ferry et al., "Autoinducers extracted from microbial mats reveal a surprising diversity of $\mathrm{N}$-acylhomoserine lactones (AHLs) and abundance changes that may relate to diel $\mathrm{pH}$," Environmental Microbiology, vol. 11, no. 2, pp. 409-420, 2009.

[41] Y. Ding, H. Feng, W. Huang, D. Shen, and M. Wang, "A sustainable method for effective regulation of anaerobic granular sludge: artificially increasing the concentration of signal molecules by cultivating a secreting strain," Bioresource Technology, vol. 196, pp. 273-278, 2015.

[42] Y. Li, J. Lv, C. Zhong, W. Hao, Y. Wang, and J. Zhu, "Performance and role of $\mathrm{N}$-acyl-homoserine lactone (AHL)-based quorum sensing (QS) in aerobic granules," Journal of Environmental Sciences, vol. 26, no. 8, pp. 1615-1621, 2014.

[43] T. T. Chen, P. Zheng, and L. D. Shen, "Growth and metabolism characteristics of anaerobic ammonium-oxidizing bacteria aggregates," Applied Microbiology and Biotechnology, vol. 97, no. 12, pp. 5575-5583, 2013.

[44] J. P. Badalamenti, Z. M. Summers, C. H. Chan, J. A. Gralnick, and D. R. Bond, "Isolation and genomic characterization of 'desulfuromonas soudanensis WTL', a Metal- and electroderespiring bacterium from anoxic deep subsurface brine," Frontiers in microbiology, vol. 7, 2016.

[45] J. Zhang, Y.-z. Zhang, B.-h. Zhao et al., "Effects of pH on AHL signal release and properties of ANAMMOX granules with 
different biomass densities," Environmental Science: Water Research \& Technology, vol. 5, no. 10, pp. 1723-1735, 2019.

[46] C. Tan, D. Cui, Y. Liu, and Y. Ji, "Influence of tourmaline on the anaerobic ammonium oxidation process in sequencing batch reactors," Journal of Environmental Engineering, vol. 143, no. 9, 2017.

[47] C. Callejas, A. Fernández, M. Passeggi et al., "Microbiota adaptation after an alkaline $\mathrm{pH}$ perturbation in a full-scale UASB anaerobic reactor treating dairy wastewater," Bioprocess and Biosystems Engineering, vol. 42, no. 12, pp. 2035-2046, 2019.

[48] Y.-F. Wang and J.-D. Gu, "Effects of allylthiourea, salinity, and $\mathrm{pH}$ on ammonia/ammonium-oxidizing prokaryotes in mangrove sediment incubated in laboratory microcosms," Applied Microbiology and Biotechnology, vol. 98, no. 7, pp. 3257-3274, 2014.

[49] D. R. Speth, S. Guerrero-Cruz, B. E. Dutilh, and M. S. M. Jetten, "Genome-based microbial ecology of anammox granules in a full-scale wastewater treatment system," Nature communications, vol. 7, no. 1, 2016.

[50] Y. Wang, J. Chen, S. Zhou et al., “16S rRNA gene highthroughput sequencing reveals shift in nitrogen conversion related microorganisms in a CANON system in response to salt stress," Chemical Engineering Journal, vol. 317, pp. 512$521,2017$.

[51] H. Vlamakis, Y. Chai, P. Beauregard, R. Losick, and R. Kolter, "Sticking together: building a biofilm the Bacillus subtilis way," Nature Reviews Microbiology, vol. 11, no. 3, pp. 157-168, 2013.

[52] Y. Qin, Y. He, Q. She, P. Larese-Casanova, P. Li, and Y. Chai, "Heterogeneity in respiratory electron transfer and adaptive iron utilization in a bacterial biofilm," Nature Communications, vol. 10, no. 1, pp. 3702-3712, 2019.

[53] V. S. Gawas, M. S. Shivaramu, S. R. Damare, D. Pujitha, R. M. Meena, and B. D. Shenoy, "Diversity and extracellular enzyme activities of heterotrophic bacteria from sediments of the Central Indian Ocean Basin," Scientific Reports, vol. 9, no. 1, pp. 9403-9409, 2019.

[54] H.-x. Lan, D. Yang, H. Zhang et al., "Effects of temperature on white water treatment by the dominant bacteria," Nordic Pulp \& Paper Research Journal, vol. 34, no. 1, pp. 133-137, 2019.

[55] H.-C. Flemming and J. Wingender, "The biofilm matrix," Nature reviews microbiology, vol. 8, no. 9, pp. 623-633, 2010.

[56] C.-J. Tang, P. Zheng, L.-Y. Chai, and X. B. Min, "Characterization and quantification of anammox start-up in UASB reactors seeded with conventional activated sludge," International Biodeterioration \& Biodegradation, vol. 82, pp. 141-148, 2013.

[57] A. Kostrytsia, S. Papirio, L. Morrison et al., "Biokinetics of microbial consortia using biogenic sulfur as a novel electron donor for sustainable denitrification," Bioresource Technology, vol. 270, pp. 359-367, 2018.

[58] E. I. Kompantseva, I. V. Kublanov, A. A. Perevalova et al., "Calorithrix insularis gen. nov., sp. nov., a novel representative of the phylum Calditrichaeota," International journal of systematic and evolutionary microbiology, vol. 67, no. 5, pp. 1486-1490, 2017.

[59] Z.-r. Chu, K. Wang, X.-k. Li, M. T. Zhu, L. Yang, and J. Zhang, "Microbial characterization of aggregates within a one-stage nitritation- anammox system using high-throughput amplicon sequencing," Chemical Engineering Journal, vol. 262, pp. 41-48, 2015.

[60] S. Tian, Z. Tian, H. Yang, M. Yang, and Y. Zhang, "Detection of viable bacteria during sludge ozonation by the combination of ATP assay with PMA-Miseq sequencing," Water, vol. 9, no. 3, p. 166, 2017.

[61] Y.-W. Cui, H.-Y. Zhang, P.-F. Lu, and Y. Z. Peng, "Effects of carbon sources on the enrichment of halophilic polyhydroxyalkanoate-storing mixed microbial culture in an aerobic dynamic feeding process," Scientific reports, vol. 6, no. $1,2016$.

[62] C. Wang, S. Liu, X. Xu, C. Zhang, D. Wang, and F. Yang, "Achieving mainstream nitrogen removal through simultaneous partial nitrification, anammox and denitrification process in an integrated fixed film activated sludge reactor," Chemosphere, vol. 203, pp. 457-466, 2018.

[63] S. Spring, P. Kämpfer, and K. H. Schleifer, "Limnobacter thiooxidans gen. nov., sp. nov., a novel thiosulfate-oxidizing bacterium isolated from freshwater lake sediment," International Journal of Systematic and Evolutionary Microbiology, vol. 51, no. 4, pp. 1463-1470, 2001.

[64] Q. Liu, M. Li, R. Liu et al., "Removal of trimethoprim and sulfamethoxazole in artificial composite soil treatment systems and diversity of microbial communities," Frontiers of Environmental Science \& Engineering, vol. 13, no. 2, 2019. 